\title{
Free thaw resistance of stabilized and fiber-reinforced soil vulnerable to landslides
}

\author{
Autores \\ K. Rajesh Kumar, R. Gobinath, G. Shyamala, Emelec Viloria, Noel Varela \\ DOI \\ https://doi.org/10.1016/j.matpr.2020.02.041
}

Palabras clave

Freeze-thaw test, Polypropylene fiber, Soil stabilization

\begin{abstract}
The research is undertaken to study the combined reinforcing and stabilizing effect of Eco sand, Metakaolin added with Polypropylene fibers in silty soil obtained from Nilgris district. In this work, an effort is made to obtain the impact of adding polypropylene fibers in fixed ratios (eco sand10\%_metakaolin 5\%) tandem with two novel stabilizing agents in various proportions (polypropylene fiber $0.1 \% \& 0.2 \%$ ) is the effects of non-traditional additives on the geotechnical properties of soils have been the focus of much investigation in recent years. It has been well established that the plasticity index and also the size, shape, and arrangement of soil particles will affect the treatment process of natural soils with additives. Stabilization of soils that are subjected to a regular variation in the temperature requires the most probable selection of suitable stabilizers and admixtures to improve the strength of the soil. This study investigates the resistance of the Nilgiris soil over the freeze-thaw reaction. The soil is stabilized with Eco Sand, Metakaolin, and polypropylene fiber (synthetic fiber). The index and engineering properties of the soil were determined in the laboratory. The soil is stabilized with two variants of an equal proportion of EcoSand-10\%, Metakaolin- $5 \%$, and varying the polypropylene fiber in a proportion of $0.1 \%$ and $0.2 \%$ with the weight of the soil. UCS test was conducted for the virgin sample as well as the sample after four freeze-thaw cycles. The soil sample is kept at $0^{\circ}$ for $24 \mathrm{~h}$ and later at $28^{\circ}$ for $24 \mathrm{~h}$ to complete a cycle. It is determined that the admixtures added has increased the resistance of the soil over the freeze-thaw reaction after the cycles. The polypropylene fiber has increased the bonding of soil, and hence it stabilizes the soil during a large periodical variation in the temperature of the soil.
\end{abstract}

